\title{
PLANTIO DE CANA-DE-AÇÚCAR EM SOLOS ARENOSOS: CONSIDERAÇÕES SOBRE O USO E OCUPAÇÃO AGRÍCOLA DA BACIA DO RIBEIRÃO SUJO, SERRANÓPOLIS-GO
}

\section{Bruna Bizarro Menezes}

Iraci Scopel

\author{
Marluce Silva Sousa
}

RESUMO: Com a perspectiva próxima da instalação de várias indústrias sucroalcooleiras no sudoeste de Goiás e o possível plantio de cana-de-açúcar em áreas antes destinadas às pastagens, principalmente em solos relativamente frágeis como os Neossolos Quartzarênicos, que caracterizam-se por ter pouca aptidão agrícola e necessitarem um manejo muito particular, merecem atenção especial os impactos ambientais nesses solos, provenientes desse tipo de atividade. Assim, essa proposta tem como objetivo tecer algumas considerações sobre o plantio de cana-de-açúcar em solos arenosos, tendo como ponto de partida a bacia do ribeirão Sujo no município de Serranópolis, estado de Goiás, que tem passado por um processo de arenização decorrente do manejo inadequado do solo. Atualmente o uso do solo predominante da bacia é o plantio de cana-de-açúcar, a utilização desses solos para atender uma monocultura tem levantado uma série de perguntas no que se refere aos prováveis impactos ambientais para a produção de cana-de-açúcar em solos referidos como arenosos, principalmente pelo uso sem muito controle de água residuária de indústria sucro- alcooleira, significando isto a água das sobras no processo produtivo do açúcar e do álcool, conhecida como vinhaça e utilizada na fertirrigação durante o ciclo de crescimento da cultura. Essa água pode conter uma quantidade significativa de 
elementos contaminantes do solo e das águas superficiais, caso não haja um manejo adequado.

PALAVRAS-CHAVE: cana-de-açúcar, cerrado brasileiro, políticas públicas, solos arenoso.

\section{INTRODUÇÃO}

O Cerrado brasileiro (Savana), localizada na porção Central da América do Sul, essa região que principalmente a partir da década de 70 recebeu vários programas de incentivos fiscais e subsídios que desencadeou uma série de processos sócioeconômicos impactantes no ambiente original, se tornou a nova fronteira agrícola do Brasil. Nesse período, vários programas de incentivo fiscais e subsídios, reflexos das transformações econômicas no país e do contexto internacional, estimularam a sua ocupação e a sua incorporação à economia nacional, gerando uma série de transformações sócio-espaciais.

Entre elas, destacam-se o aumento populacional, provocado por migrações, o crescimento e o desenvolvimento urbano e a implantação de um sistema agropecuário moderno com transformações significativas no campo.

O novo modelo de desenvolvimento no Cerrado, intensificou o uso da terra ocupando-se primeiramente as terras mais adequadas, tanto em relação aos solos (Latossolos) quanto ao clima e, posteriormente, abrangendo áreas de solos arenosos (os Neossolos Quartzarênicos órticos típicos), não indicadas para práticas agropecuárias intensivas. A vegetação original foi substituída por pastagens plantadas ou por monoculturas.

Quando tais atividades são praticadas, sem um manejo conservacionista, há uma redução no teor de matéria orgânica, na capacidade de armazenamento de água, na fertilidade e na produtividade do solo, um aumento na exposição e desagregação do solo, 
fortalecendo os processos erosivos, com perdas de solo e água, provocando o surgimento de sulcos e voçorocas e assoreamento dos vales.

Sabe-se que os solos de textura arenosa (areia e areia franca) são considerados muito frágeis e/ou marginais em relação à sua utilização agrícola e no ecossistema a que pertencem. O uso intensivo desses solos, portanto, é restrito, principalmente pela baixa capacidade de armazenamento de água e alta suscetibilidade à erosão, dentre outros aspectos (MACEDO, 1994; SPERA et al., 1999; MACEDO et al., 1998; OLIVEIRA et al., 2002).

Entretanto, observa-se a falta de detalhamento prático para aplicação de algumas sugestões relativas ao estudo e ao uso de solos arenosos no Cerrado brasileiro, causando a preocupação com o possível agravamento dos problemas sociais e ambientais neste tipo de solo, como já tem acontecido no sudoeste do estado de Goiás, com a degradação em formas de "areais"1.

Neste sentido, é necessário um enfoque geossistêmico, que considere os aspectos sócio-econômicos (MONTEIRO, 2002), e a possibilidades da aplicação de novas tecnologias para a sua utilização, sem causar danos ambientais, tais como aumentar a matéria orgânica do solo e melhorar a cobertura do solo através de resíduos culturais, visando com isso também aumentar a capacidade de armazenamento de água (CAD) no solo. A redução das práticas mecânicas de cultivo ou, até mesmo, o plantio direto são considerados importantes para viabilizar o cultivo nos solos arenosos uma vez que sua estrutura predominante é de grãos simples.

Fenômenos insólitos de manchas esparsas de solo desnudo ocorrem na região do sudoeste goiano em uma área de 600 mil hectares de Neossolos Quartzarênicos (RQ). Tais manchas parecem estar relacionadas à tradição agrícola regional de desmatamento e uso desse solo com pastagem e pecuária extensiva, aproveitando-se as suas reservas naturais de nutrientes. Com o passar do tempo (cinco a sete anos) esgotam-se as

\footnotetext{
${ }^{1}$ Os areais são manchas de Neossolos Quartzarênicos, sem ou com rara cobertura vegetal, resultantes da degradação do solo in situ e/ou da deposição de areia transportada, e expostos a processos erosivos. Caracterizam-se, sobretudo, pela dificuldade de revegetação ou, quando esta ainda existe, pelas poucas espécies que a compõem.
} 
reservas de nutrientes e a qualidade de vida que está necessariamente vinculada ao uso econômico da terra decresce para as populações que direta ou indiretamente a exploram (SCOPEL, 2003).

Os impactos ambientais das atividades agrícolas são em geral tênues bastante dependentes de fatores pouco controláveis (chuvas, temperaturas, ventos etc.), atingindo grandes áreas de forma pouco precisa, freqüentemente crônica, pouco evidente, intermitente e de difícil quantificação (perda de solos, produção de gases, erosão genética, contaminação de águas subterrâneas com fertilizantes ou pesticidas, etc.). Em muitos casos, os piores impactos ambientais da agricultura são invisíveis aos olhos da população, dos consumidores e dos próprios agricultores.

Os sistemas de produção da cana-de-açúcar ainda são bastante heterogêneos a nível nacional, no que pese a modernização tecnológica dessa atividade. O setor canavieiro emprega desde tecnologias de ponta até práticas que datam do neolítico, como o uso das queimadas para facilitar a colheita. A evolução tecnológica do cultivo da cana-de-açúcar é constante, mas diferenciada segundo os interesses e as estratégias das empresas. Nesse sentido, a visão e as possibilidades de gestão do impacto ambiental do cultivo para um pequeno plantador-fornecedor são, obrigatoriamente, diferentes das de um grande empresário do setor.

Esta situação problemática é notável na bacia do Ribeirão Sujo, afluente da margem direita do Rio Verde, que abrange uma área de 164 km² no município de Serranópolis, no sudoeste do estado de Goiás sendo constituída, predominantemente, por solos arenosos ${ }^{2}$. Esta bacia é um exemplo da apropriação dos recursos e transformação da paisagem natural pelo moderno processo de produção ligado à monocultura da cana-de-açúcar e à plantação de pastagens, que a modificaram substancialmente, imprimindo-lhe degradação intensa.

\footnotetext{
1 São considerados solos arenosos aqueles cuja textura é constituída por mais de $85 \%$ de areia, isto é, grãos maiores que $0,02 \mathrm{~mm}$.

Programa que promoveu a produção de álcool de cana-de-açúcar para substituir os combustíveis derivados do petróleo, produto que estava em crise no fim da década de 1970.
} 
$\mathrm{Na}$ bacia do Ribeirão Sujo, que tinha como uso do solo predominante a pecuária, foi instalada, sob incentivo do Programa Proálcool ${ }^{2}$, a empresa Goálcool, no inicio da década de 1980. Essa empresa utilizou uma grande área para o plantio de cana-deaçúcar por cerca de 6 anos, seguida da implantação de pastagem. Esta área, atualmente, está em parte sendo utilizada com pastagens ou abandonada e encontra-se bastante degradada, algumas manchas de areia apresentando-se sem cobertura vegetal. As antigas instalações da empresa encontram-se arrendadas à empresa Energética Serranópolis Ltda, que já está cultivando cana-de-açúcar novamente (SOUZA, 2006).

A produção de cana-de-açúcar na bacia do Ribeirão Sujo, sob responsabilidade da energética Serranópolis, utiliza solos arenosos e solos de textura média, não existe nenhum tipo de cuidado especial com solo no processo de cultivo, as mesmas técnicas empregadas aos solos de textura média são utilizadas nos solos arenosos. Apesar disso a produtividade da cultura é satisfatória, uma vez que a cultura da cana-de-açúcar não exige grandes cuidados, a usina realiza um preparo prévio do solo com correção e adubação, e matem a irrigação nos primeiros estádios de desenvolvimento da cultura.

Em outras áreas da bacia solos arenoso que em outros momentos foram utilizados para agricultura ou pastagem, e não receberam manejo adequado e após o esgotamento das reservas naturais do solo foram de certa forma "abandonado" sem nenhum tipo de reconstituição da forma original, hoje são areais de proporções consideráveis.

Assim, os objetivos deste trabalho: i) analisar como se deu a incorporação dos Neossolos Quartzarênicos ao processo produtivo regional no Cerrado, especialmente na bacia do Ribeirão Sujo; ii) observar os impactos resultantes do uso desse solos para o plantio de cana-de-açúcar; iii) apontar alternativas para a utilização dos solos arenosos.

\section{DESENVOLVIMENTO}

A bacia do ribeirão sujo está localizada no município de Serranópolis, estado de Goiás, como podemos ver na Figura 1, a área em destaque é a área cultivada com canade-açúcar. 


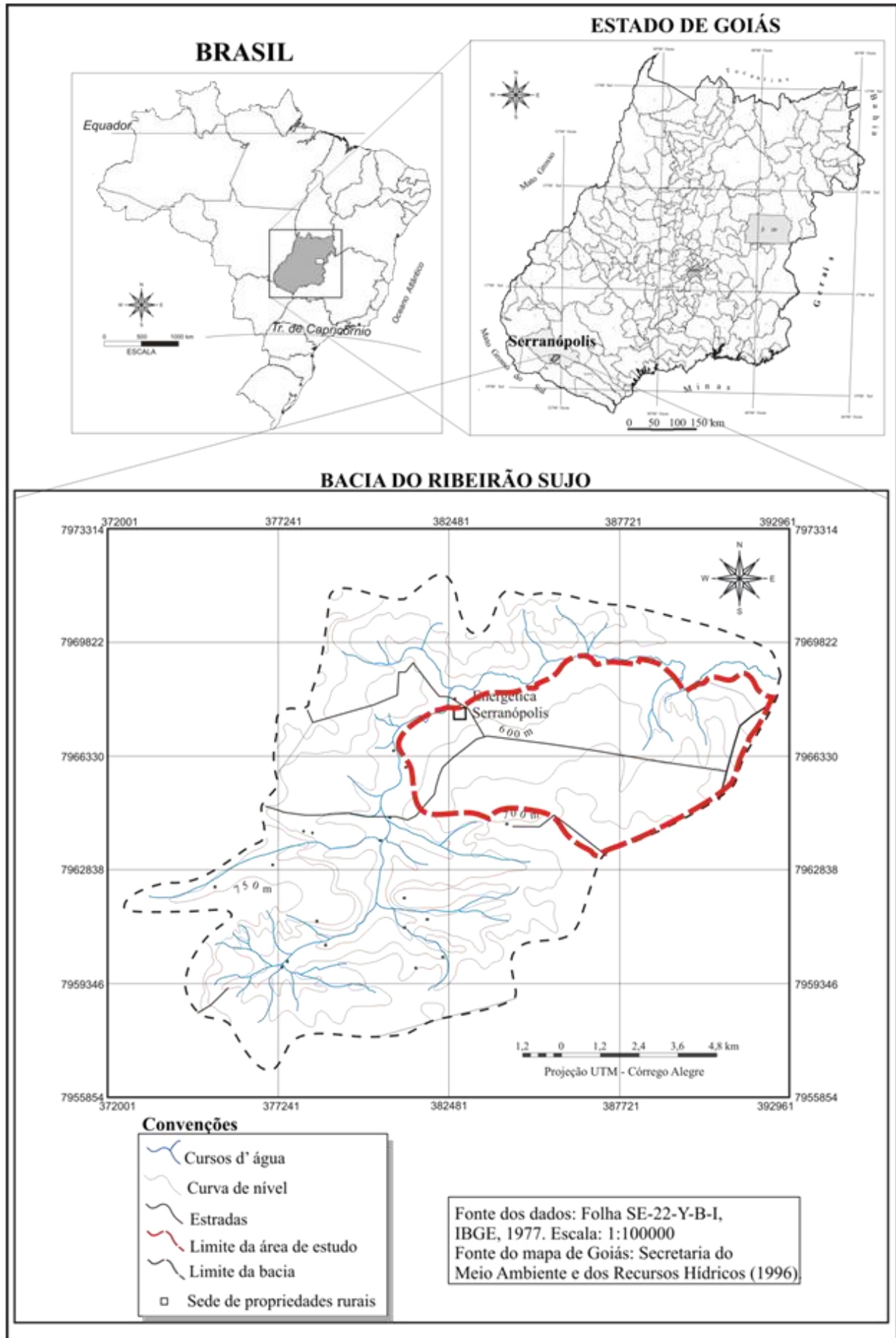

Figura 1. Localização da área de estudo.

A microrregião Sudoeste de Goiás, onde está localizado o município de 
Serranópolis, atravessou diferentes fases em sua economia e guardou as marcas adquiridas em todas elas (ESTEVAM, 1998). Primeiro, foi ocupada por grupos indígenas há milênios; na história recente explorou a pecuária extensiva; posteriormente ingressou na agricultura comercial do arroz e feijão atendendo à demanda dos cerealistas do Triângulo Mineiro. Atualmente, a região constitui um dos pólos mais avançados de Goiás no setor agropecuário e agroindustrial. Estas fases econômicas constituem parte de processos sociais (políticos, econômicos, culturais) que, a partir da relação sociedade/natureza, modificam o espaço e estabelecem novos arranjos espaciais e novas funções e formas para a paisagem.

Foram muitos os processos econômicos exploratórios que ocorreram no Cerrado, porém os das últimas décadas modificaram drasticamente a paisagem do sudoeste de Goiás, como um todo, e da bacia do Ribeirão Sujo, particularmente. Numa área em que a vocação agrícola sempre foi subestimada, especialmente por causa das limitações do solo, tem-se a maior região em terras cultivadas de Goiás, sendo o maior criador de bovinos, o maior produtor de arroz, de milho e de soja (ESTEVAM, 1998; ARRAIS, 2004). Além da produção e da área plantada, a produtividade é notável em virtude das técnicas adotadas no processo de produção voltado, essencialmente, para a exportação.

A despeito do "abandono" que o caracterizou até meados do século XX, uma série de mudanças deu dinamismo à produção agrícola no Cerrado a partir daquele momento: a criação de políticas públicas de fomento para a agricultura brasileira, com contribuição fundamental de recursos públicos, como políticas de crédito rural, extensão, pesquisa e política de seguro; o desenvolvimento da infra-estrutura de transporte, principalmente o rodoviário, que facilitou o escoamento da produção regional; a diversificação da pauta de exportação; a adaptação de variedades de plantas para as condições de clima e solos no Cerrado; mudança no padrão alimentar da população, como a substituição do consumo de gordura de porco pelo consumo de óleos vegetais, principalmente de soja, etc. (FERREIRA, 2001).

As transformações no uso da terra, por serem relacionadas às formas e 
funções espaciais, são aquelas que melhor representam a dinâmica da paisagem entre 1965 e 205. As áreas agrícolas e as pastagens plantadas agora são dominantes em detrimento da vegetação natural, como demonstra o mapeamento realizado para o sudoeste de Goiás (SCOPEL; PEIXINHO; SOUSA, 2005) e para a bacia do Ribeirão Sujo. O uso da terra é um aspecto no interior de um sistema espacial, de um domínio total; é o resultado da apropriação total do espaço rural que tem, em cada lugar, formas específicas.

Logo, a conjuntura sócio-econômica internacional e nacional relacionada aos fatores locais, internos, demandou novas funções aos elementos espaciais o que imprimiu novas formas, determinando a transformação da paisagem natural numa paisagem transformada, com novo valor dentro do sistema produtivo regional. Isso é claramente perceptível na análise da evolução do uso da terra no sudoeste de Goiás e na bacia do Ribeirão Sujo.

No sudoeste de Goiás a atividade pecuária desenvolvia-se nos vales onde predominavam pastagens naturais e/ou cultivadas com capins Jaraguá (Hyparrbenia rufa) e Colonião (Panicum maximum), que exigem uma maior fertilidade natural dos solos. Os chapadões eram utilizados apenas nos meses chuvosos, quando havia disponibilidade de água para suprir as necessidades do gado, como já foi dito. Já a utilização das terras para lavouras era restrita às proximidades dos vales.

O uso cada vez mais freqüente de sementes desenvolvidas em laboratórios, fertilizantes, herbicidas, plantio em entressafra e uso de créditos públicos expressam que a modernização da agricultura espacializa no campo o meio técnico-científicoinformacional, caracterizado por profunda interação entre ciência e técnicas, dada sob égide do mercado, com tendência a ser global. As transformações da paisagem pela apropriação da natureza ocorrem, agora, subordinadas a essa lógica (técnica-ciênciamercado), de modo que se pode falar de uma cientifização ou tecnicização da paisagem (SANTOS, 2002).

Nesta perspectiva, com a ampliação crescente das lavouras temporárias e das pastagens, a partir dos estímulos à abertura de áreas pelas políticas públicas, a exemplo 
do Goiás Rural, do governo estadual, o desmatamento da vegetação de cerrado foi inevitável. Oliveira (2002) constatou que, no entorno do município de Jataí, abrangendo área a leste de Serranópolis, em 1967, as áreas de cerrado e matas correspondiam a cerca de metade da cobertura da terra. Se somado este tipo de vegetação com o cerrado utilizado com pecuária, chega-se a praticamente 100\% do uso da terra. Já em 1997, com a consolidação da modernização, a área de pecuária correspondia a 57\%, de cerrado com pecuária $8 \%$, de agricultura $23 \%$ e o cerrado e matas, juntos, correspondiam a apenas $10 \%$ do total da cobertura da terra.

Atualmente a Energética Serranópolis tem 9424.56 há de terra cultivados com cana-de-açúcar, tendo uma produção de 85,5 toneladas de açúcar por hectare. Através de dados informais, foi possível constatar que a usina não tem controle sobre a aplicação de vinhaça no solo, a cultura recebe a fertirrigação durante os três primeiros meses após o plantio, 0 regime de chuvas na região apresenta grande variabilidade pluviométrica e com muita ocorrência de veranicos, porém não é realizada irrigação emergencial na lavoura.

Apesar do manejo "simples", a cana-de-açúcar aparentemente é adaptada a esse tipo condições de solo e clima, nas analises de solos realizadas na área estudada, não foi encontrado nenhum elemento químico em concentrações prejudiciais ao solo e a planta, porém estão a baixo do recomendado para atingir o potencial produtivo da cultura, como demonstra a Tabela 1. Foram coletadas 30 amostras em três profundidade $0-5 \mathrm{~cm} \mathrm{10-20}$ $\mathrm{cm}$ e 40-60 cm, devido ao grande volume de dados, para este trabalho usaremos amostras significativas.

\begin{tabular}{|c|c|c|c|c|c|c|c|c|c|c|c|c|}
\hline \multirow[b]{2}{*}{$\mathbf{P}$} & \multirow[b]{2}{*}{ Profundidade } & \multirow{2}{*}{$\begin{array}{l}\text { descrição da } \\
\text { paisagem }\end{array}$} & \multirow[b]{2}{*}{$p H$} & \multicolumn{6}{|c|}{$\left(\mathrm{Cmolc} / \mathrm{dm}^{3}\right)$} & \multicolumn{2}{|c|}{$\left(m g / d m^{3}\right)$} & \multirow{2}{*}{\begin{tabular}{|l|}
$\mathrm{g} / \mathrm{kg}$ \\
M.O.
\end{tabular}} \\
\hline & & & & Al & $\mathrm{Ca}$ & $\mathrm{Ca}+\mathrm{Mg}$ & Mg & $\mathrm{H}+\mathrm{Al}$ & K & K & $\mathbf{P}$ & \\
\hline 1 & $0-5$ & Cana & 6,77 & 0,23 & 2,84 & 3,82 & 0,98 & 0,00 & 0,04 & 15,60 & 10,46 & 7,24 \\
\hline 1 & $10--20$ & Cana & 6,02 & 0,32 & 0,94 & 1,67 & 0,73 & 1,53 & 0,068 & 26,52 & 1,80 & 9,06 \\
\hline 1 & $40-60$ & Cana & 5,94 & 0,68 & 0,49 & 1,48 & 0,99 & 0,58 & 0,08 & 31,20 & 0,72 & 7,69 \\
\hline
\end{tabular}




\section{FÓRUM AMBIENTAL DA ALTA PAULISTA}

Volume VI - Ano 2010

Instituição Organizadora: ANAP - Associação Amigos da Natureza da Alta Paulista

\begin{tabular}{|c|c|c|c|c|c|c|c|c|c|c|c|c|}
\hline 2 & $0-5$ & $\begin{array}{c}\text { Cana } \\
\text { Queimada }\end{array}$ & 6,10 & 0,13 & 2,45 & 3,33 & 0,88 & 0,00 & 0,06 & 23,40 & 3,25 & 12,06 \\
\hline 2 & $10--20$ & $\begin{array}{c}\text { Cana } \\
\text { Queimada }\end{array}$ & 6,05 & 0,39 & 1,32 & 2,52 & 1,20 & 1,68 & 0,02 & 7,80 & 1,80 & 11,66 \\
\hline 2 & $40-60$ & $\begin{array}{c}\text { Cana } \\
\text { Queimada }\end{array}$ & 5,60 & 2,14 & 0,07 & 0,80 & 0,73 & 1,45 & 0,02 & 7,80 & 1,08 & 5,18 \\
\hline 3 & $40-60$ & $\begin{array}{c}\text { Cana } \\
\text { Queimada }\end{array}$ & 5,65 & 1,14 & 0,29 & 0,89 & 0,6 & 0,00 & 0,02 & 7,80 & 1,08 & 3,93 \\
\hline 3 & $0-5$ & $\begin{array}{c}\text { Cana } \\
\text { Queimada }\end{array}$ & 5,99 & 0,48 & 1,19 & 1,84 & 0,65 & 0,41 & 0,06 & 23,40 & 2,89 & 14,43 \\
\hline 3 & $10--20$ & $\begin{array}{c}\text { Cana } \\
\text { Queimada }\end{array}$ & 5,61 & 1,06 & 0,31 & 0,96 & 0,65 & 1,01 & 0,032 & 12,48 & 1,08 & 5,76 \\
\hline 4 & $40-60$ & Cana & 5,56 & 1,32 & 0,20 & 0,59 & 0,39 & 0,00 & 0,016 & 6,24 & 1,44 & 4,00 \\
\hline 4 & $0-5$ & Cana & 6,8 & 0,25 & 1,88 & 2,43 & 0,55 & 0,00 & 0,044 & 17,16 & 2,52 & 7,88 \\
\hline 4 & $10--20$ & Cana & 5,89 & 1,50 & 0,75 & 1,36 & 0,61 & 0,46 & 0,032 & 12,48 & 1,44 & 6,05 \\
\hline 5 & $40-60$ & Pastagem & 5,85 & 1,19 & 0,40 & 1,69 & 1,29 & 0,31 & 0,024 & 9,36 & 1,44 & 4,04 \\
\hline 5 & $0-5$ & Pastagem & 6,44 & 0,30 & 1,98 & 2,43 & 0,45 & 2,03 & 0,032 & 12,48 & 5,05 & 6,70 \\
\hline 5 & $10--20$ & Pastagem & 6,05 & 0,90 & 0,48 & 0,92 & 0,44 & 0,12 & 0,02 & 7,80 & 1,41 & 8,75 \\
\hline 6 & $0-5$ & Cana & 6,43 & 0,0 & 5,20 & 6,05 & 0,85 & 0,00 & 0,024 & 9,36 & 11,90 & 11,64 \\
\hline 6 & $10--20$ & Cana & 6,85 & 0,00 & 4,03 & 4,51 & 0,48 & 0,00 & 0,016 & 6,24 & 5,41 & 11,73 \\
\hline 6 & $40-60$ & Cana & 6,46 & 0,00 & 3,35 & 4,03 & 0,68 & 0,00 & 0,012 & 4,68 & 1,44 & 5,50 \\
\hline 7 & $0-5$ & Cana & 6,08 & 0,19 & 1,77 & 2,66 & 0,89 & 1,30 & 0,032 & 12,48 & 3,25 & 7,10 \\
\hline 7 & $10--20$ & Cana & 5,85 & 0,50 & 0,34 & 0,97 & 0,63 & 0,61 & 0,048 & 18,72 & 1,44 & 5,82 \\
\hline 7 & $40-60$ & Cana & 5,16 & 1,00 & 0,28 & 0,73 & 0,45 & 0,48 & 0,064 & 24,96 & 0,72 & 4,68 \\
\hline 8 & $0-5$ & Cana & 5,88 & 1,24 & 1,42 & 2,90 & 1,48 & 3,66 & 0,072 & 28,08 & 5,41 & 14,95 \\
\hline 8 & $40-60$ & Cana & 5,10 & 2,20 & 0,43 & 0,77 & 0,34 & 1,06 & 0,032 & 12,48 & 1,44 & 6,39 \\
\hline 8 & $10--20$ & Cana & 5,09 & 2,23 & 0,58 & 1,19 & 0,61 & 1,47 & 0,028 & 10,92 & 0,72 & 8,12 \\
\hline
\end{tabular}

Em quase todas as amostras houve variação de concentração dos elemento químicos no perfil do solo, o que mais chama a atenção é a pouca 
diferença da concentração dos elementos nos solos de cerrado e os solos que são corrigidos e adubados, isso pode estar associado a baixa capacidade do solo em reter nutrientes, pela facilidade do escoamento superficial.

A Figura 2, temos a comparação da distribuição das diferentes porcentagens de areia no solo, existe uma variação ao longo do perfil, nota-se que em algumas áreas principalmente ao sul da unidade de paisagem, uma concentração de argila na superfície $(0-5 \mathrm{~cm})$ e a $40-60 \mathrm{~cm}$. É muito interessante notar na profundidade de $10-20 \mathrm{~cm}$ a ocorrência de uma homogeneização da concentração de areia, quase toda área em 90\% de areia.

Essa variação da distribuição dos teores de areia nas amostras será aprofundada em estudos futuros, afim de compreender melhor essa ocorrência, e como esse processo pode estar relacionado com a movimentação da argila e do silte no perfil do solo.

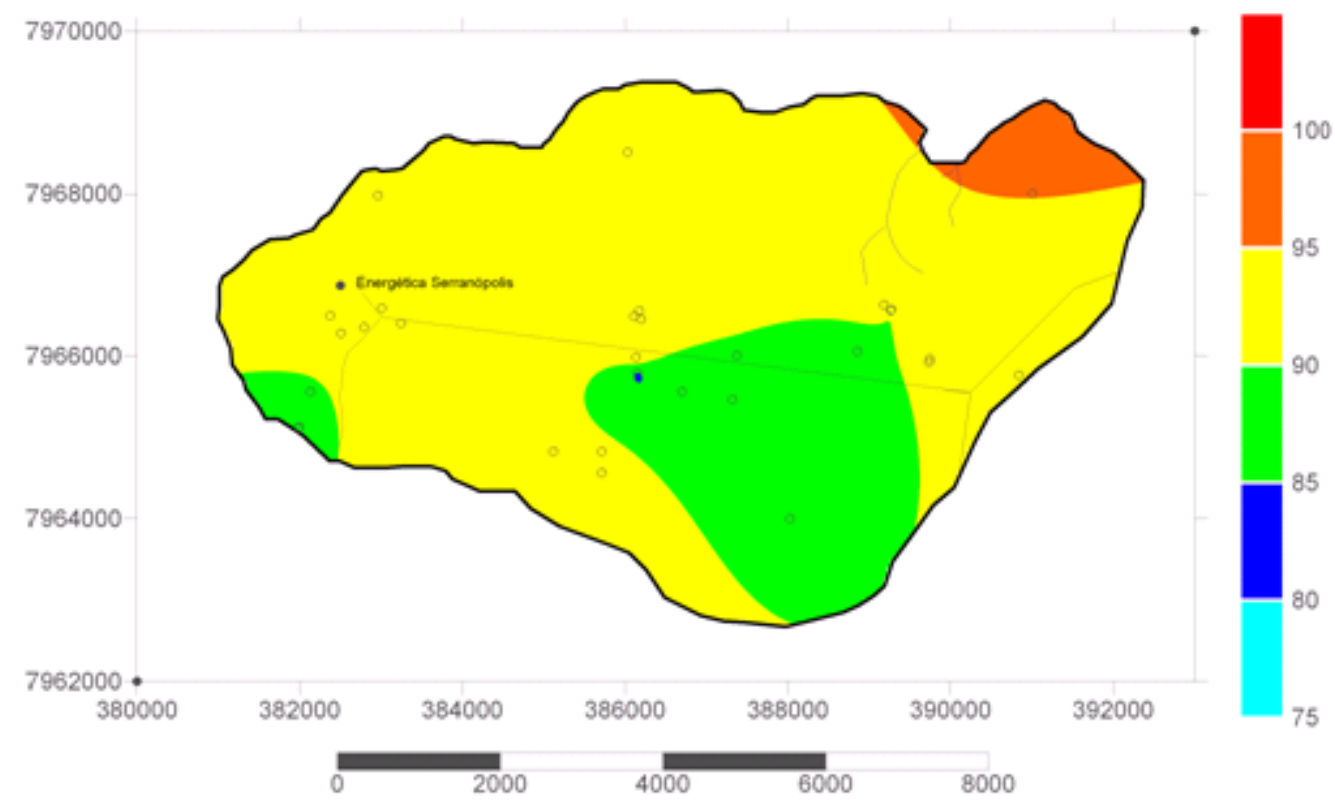




\section{Periódica Eletranica \\ FÓRUM AMBIENTAL DA ALTA PAULISTA}

Volume VI - Ano 2010

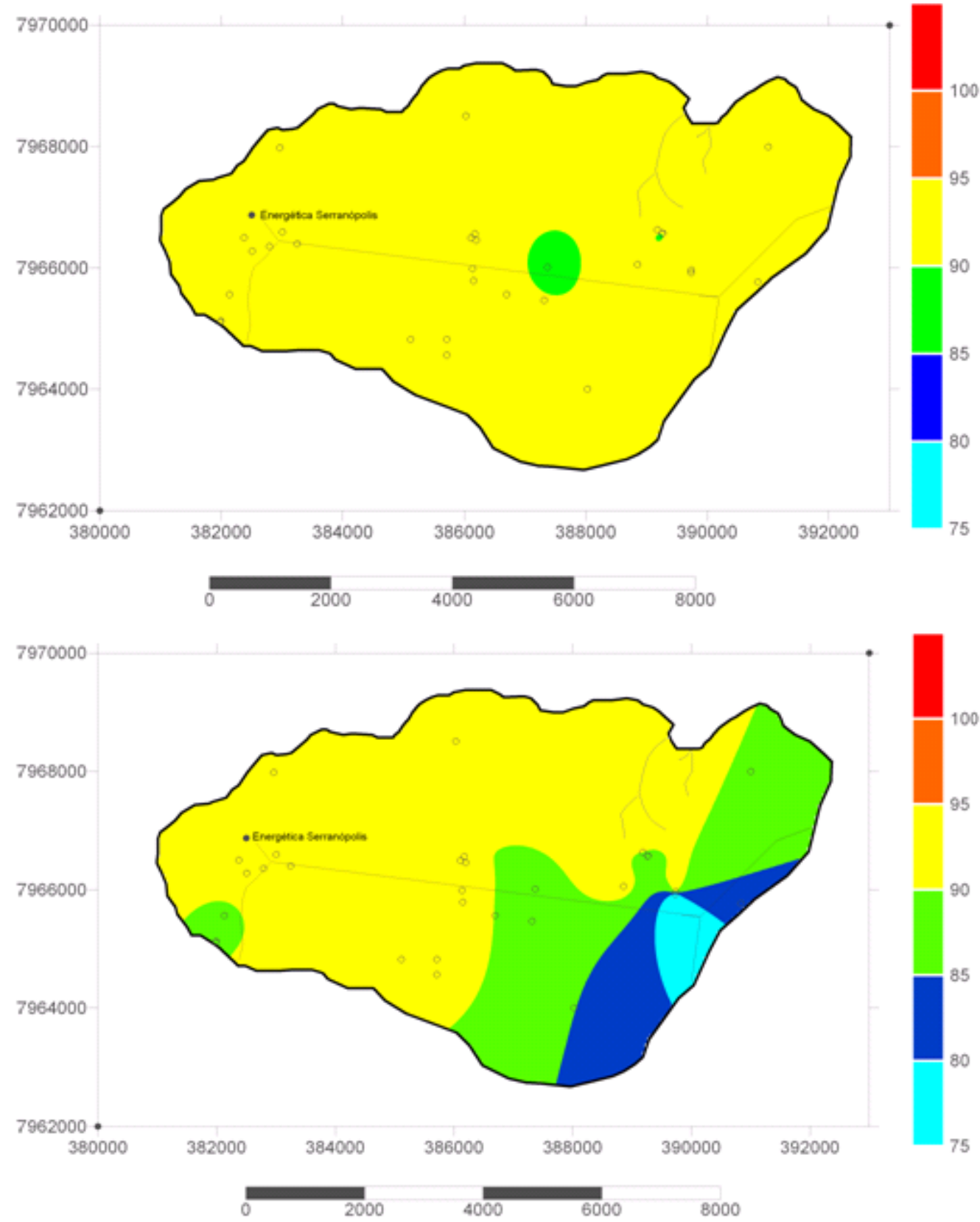

Figura 2. Espacialização da fração areia em \%, em três diferentes profundidades $0-5 \mathrm{~cm}, 10$ $20 \mathrm{~cm}$ e 40-60 cm respectivamente. Os pontos representado pelo símbolo (o) são os pontos de coletas das amostras de solo, ponto representado pelo ( $)$ representa a sede da energética Serranópolis, o traçado ( $\rightarrow$ representa a drenagem existente na área de estudo, $(\neg)$ representa estradas de acesso à energética Serranópolis. 
Na Figura 3, estão espacializados os dados da fração silte e argila do solo. No primeiro mapa estão os dados da fração silte, os valores predominantes estão entre $2 \% \mathrm{e}$ $6 \%$, sendo na região sul da área ocorre a maior concentração do elemento.

No segundo mapa que representa a fração argila, mostra que apenas na região sul, a média percentual de argila está em $11 \%$. No restante da área, entretanto, a média está em $3 \%$ de argila. A baixa quantidade de argila e a alta quantidade de areia fazem com que esses solos tenham pouca capacidade de armazenamento de água. Assim, a água infiltra com bastante facilidade no perfil do solo e apenas uma pequena quantidade dessa água fica retida; a maior parte vai para o lençol freático. A grande quantidade de areia e a pouca quantidade de argila tornam o solo friável e sem estrutura, facilmente lixiviado e erodido.

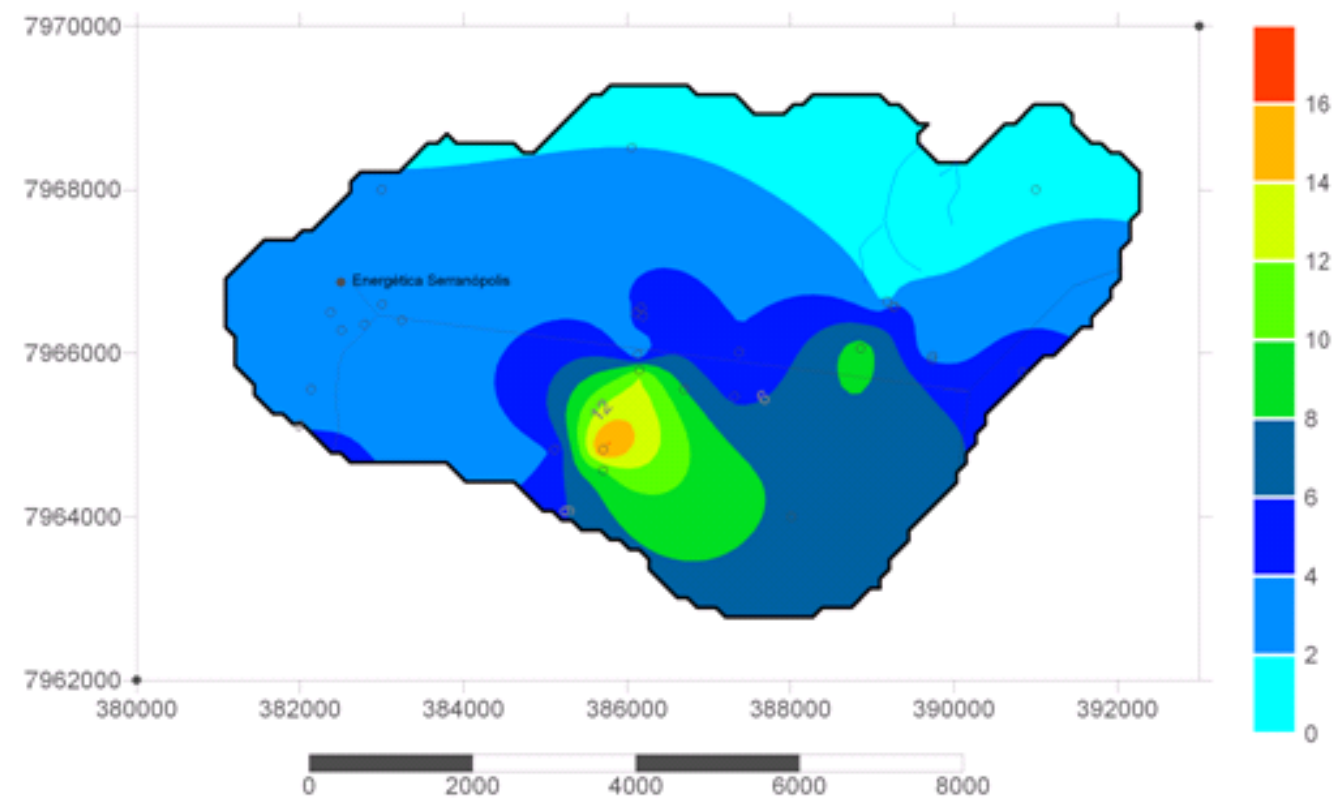



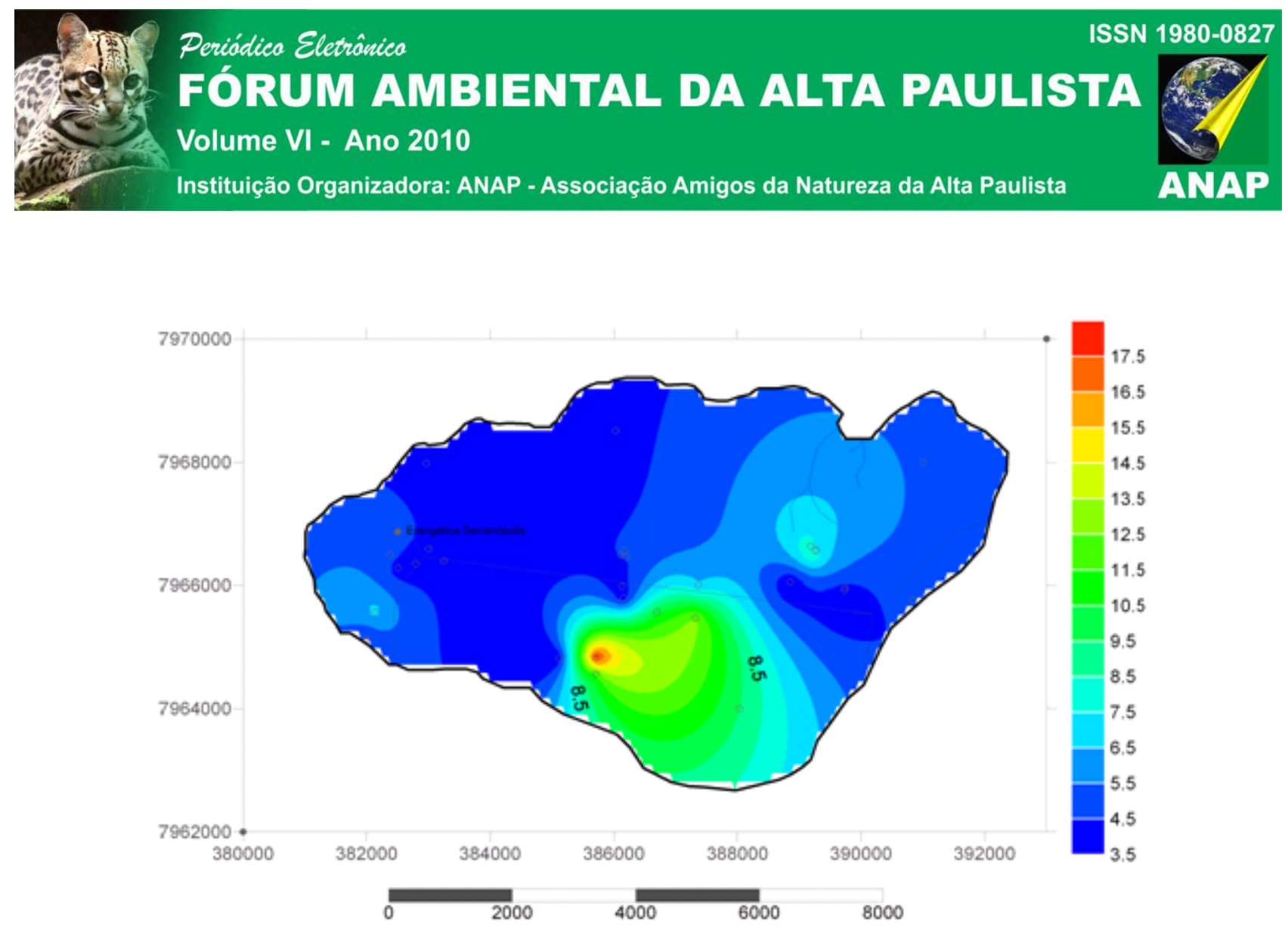

Figura 3. Espacialização da fração silte e argila em \%, respectivamente. Os pontos representado pelo símbolo (o) são os pontos de coletas das amostras de solo, ponto representado pelo ( •) representa a sede da energética Serranópolis, o traçado $(\rightarrow$ representa a drenagem existente na área de estudo, $(\sim)$ representa estradas de acesso à energética Serranópolis.

A Figura 4, estão fotos dos areais da bacia do Ribeirão Sujo e o cultivo de cana-de-açúcar. 

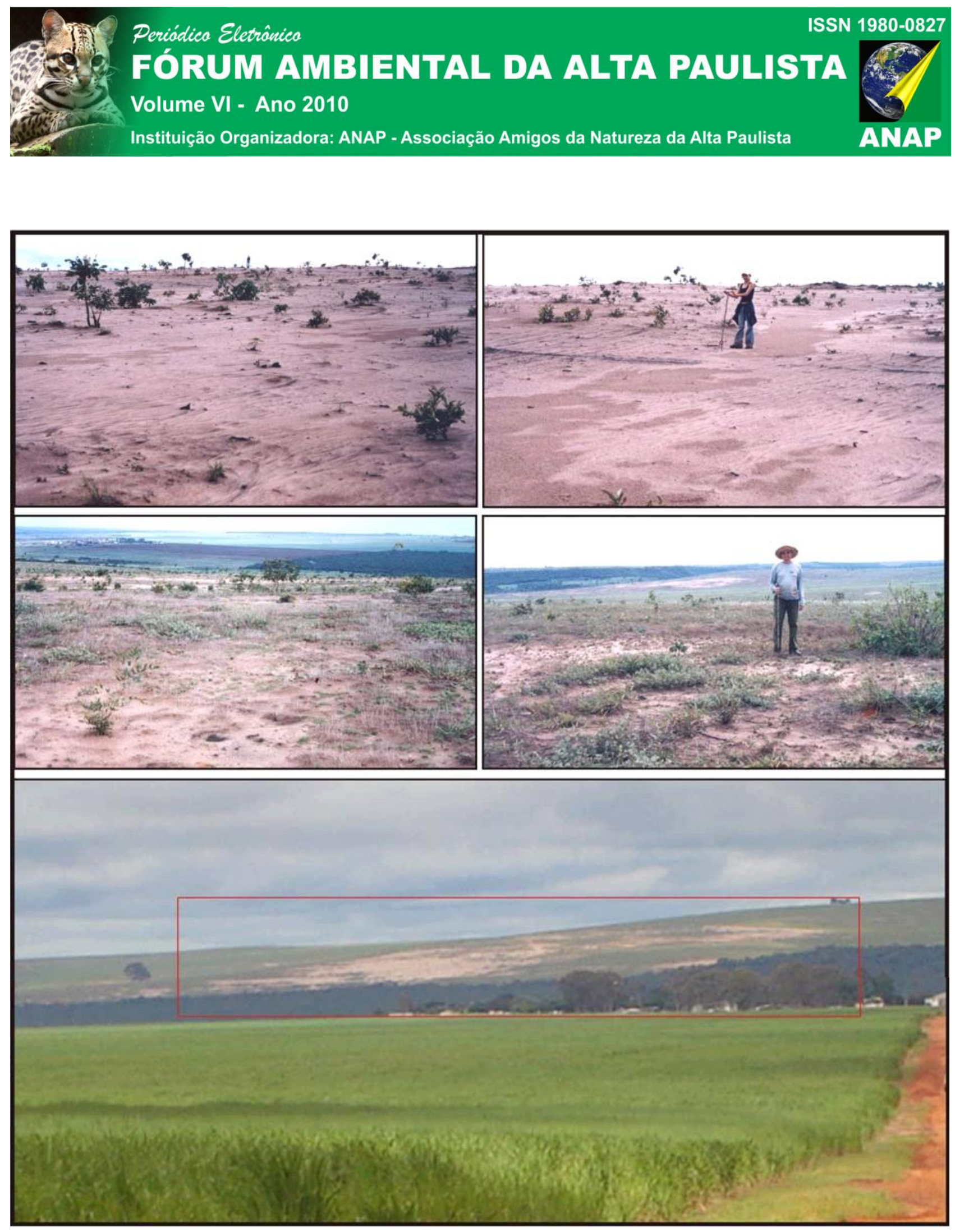

CONCLUSÃO 
A exploração dos recursos naturais ocorreu de diversas formas de acordo com o período histórico, e foi intensificando o uso exploratório dos recursos naturais a cada década, a preocupação com a preservação é uma questão recente, e em alguns casos a degradação foi tão intensa que não é viável economicamente a recuperação da área, e elas foram abandonadas. Esse foi o caso de grande parte da área da bacia do Ribeirão Sujo em Serranópolis, mais que pode ser exemplo para muitas outras áreas, que passaram por processos semelhantes.

Apesar da não ocorrência de areais na área com cultivo de cana-de-açúcar, através dos dados apresentados é possível verificar que são solos essencialmente arenosos, com baixa fertilidade, a cultura da cana-de-açúcar está aparentemente adaptada a varabilidade climáticas e as limitações do solo, porém a utilização desses solos devem ser acompanhado de um manejo especial principalmente em relação ao solo.

Ainda que a cana-de-açúcar seja rentável economicamente, a melhor forma de utilização desses solos é a preservação da vegetação nativa, uma vez retirada essa vegetação não é possível que aja uma regeneração natural, é necessário um árduo trabalho humano para recompor a paisagem do cerrado, se apenas predominar 0 abandono, a tendência é que o areal se expanda.

\section{REFERÊNCIAS}

ARRAIS, T. A. Geografia contemporânea de Goiás. Goiânia: Vieira, 2004.

ESTEVAM, L., $O$ tempo da transformação: estrutura e dinâmica da formação econômica de Goiás. Goiânia: 1998.

FERREIRA, D. F. Análise das transformações recentes na atividade agrícola da região Sudoeste de Goiás, 1970/1995-96. Uberlândia: UFU, 2001. 145 f. Dissertação (Mestrado em Desenvolvimento Econômico). Universidade Federal de Uberlândia, 2001.

MACEDO, J. Solos dos Cerrados. In.: PEREIRA, V. de Paula; FERREIRA, M. E.; PESSÔA DA CRUZ, M.C. (Eds). Solos Altamente Suscetíveis à Erosão. UNESP/JABOTICABAL/SP e SBCS/VIÇOSA/MG. 1994. p 69-76. 
MONTEIRO, C. A. de F. Sobre a desertificação no Nordeste brasileiro e a participação do homem nesse processo. Intergeo, Rondonópolis/MT, v. 2, n. 2, p. 03-35, 2002.

OLIVEIRA, I. J. Solo pobre, terra rica: paisagens do Cerrado e agropecuária modernizada em Jataí, Goiás. 2002. 160 f. Dissertação (Mestrado em Geografia). Faculdade de Filosofia, Letras e Ciências Humanas, Universidade de São Paulo. São Paulo, 2002

SANTOS, M. A natureza do espaço. São Paulo: Edusp, 2002.

SCOPEL, I. O processo de arenização no Sudoeste Goiano. In: Congresso Brasileiro de Geografia Física Aplicada, 10, Rio de Janeiro/RJ, Anais..., 2003.

SCOPEL, I.; PEIXINHO, D. M.; SOUSA, M. S. A formação de areais e seu controle na região de Jataí e Serranópolis/GO. Relatório final do Projeto. Jataí/GO: PROINPE/SECTEC-GO, 2005. $155 \mathrm{f}$.

SOUZA, M. S. As Transformações da Paisagem: contribuição ao estudo da formação de areais na bacia do Ribeirão Sujo, município de Serranópolis/GO. 2006. 205 f. Dissertação (Mestrado em Geografia) - Instituto de Estudos Sócio-ambientais. Universidade Federal de Goiás, 2006.

SPERA, S. T., et al. Solos areno-quartzosos no Cerrado: problemas, características e limitações ao uso. Planaltina/DF: Embrapa Cerrados, 1998. 48p. (Documentos n.7).

SPERA, S. T., et al. Solos areno-quartzosos no Cerrado: problemas, características e limitações ao uso. Planaltina/DF: Embrapa Cerrados, 1998. 48p. (Documentos n.7). 